\title{
PEMETAAN MELALUI FOTO UDARA PADA LAHAN MARGINAL (TIDUR) YANG BERPOTENSI UNTUK DIJADIKAN LAHAN PERKEBUNAN DI DESA BINAMANG, KECAMATAN XIII KOTO KAMPAR, KABUPATEN KAMPAR, PROVINSI RIAU
}

\author{
Nazarudin*1, Kaspul Anuar ${ }^{2}$, Warman Fatra ${ }^{3}$, Awaludin Martin ${ }^{4}$, Asral $^{5}$ \\ 1,2,3,4,5 Jurusan Teknik Mesin, Fakultas Teknik, Universitas Riau, Pekanbaru, Indonesia. \\ "E-mail: nazarudin@eng.unri.ac.id
}

\begin{abstract}
The area of Binamang Village has potential area to develop its plantation. Besides being suitable for planting oil palm and rubber commodities, Binamang village is also suitable to be developed by its plantations in the commodities of brown, gambier and gaharu. This is also supported by the large amount of marginal (non productif) land that has not been used in the village of Binamang. However, some of these margina area are the Koto Panjang PLTA lake catchment area. Clear and detailed mapping is need to classify of marginal area which is potential to be used as plantation land in this area. This is done so that there will be no conflicts in the future. In addition, this mapping data is also useful as information data for potential investors who intend to invest their funds in the plantation sector in Binamang Village.

To classify the marginal area which is not the Koto Panjang hydropower (PLTA) lake catchment area, a team of lecturers from the Mechanical Engineering Department of the University of Riau carried out community service activities in the village of Binamang, in the form of build maps of marginal area that could potentially be used as plantation / agriculture. This map is equipped with a geospatial information system. This mapping activity was carried out by using aerial photographing methods through Unmanned Aircraft by involving students of Riau University and local village equipment. This aerial photography activity is carried out at an altitude of 250 meters above ground level. With this method, all marginal areas in Binamang village can be mapped quickly and in detail.

Based on calculations carried out through aerial photographic maps that have been injected with GPS coordinates, the marginal area that has the potential to be developed into plantations in Binamang Village is about 40 hectares. This result can be a reference for relevant stakeholders in planning the development of plantation areas in Binamang Village. The results of aerial maps can also be used by local policy makers in planning the spatial layout of Binamang Village.
\end{abstract}

Keywords- Land, Village, Marginal.

\begin{abstract}
Abstrak
Wilayah Desa Binamang berpotensi untuk dikembangkan area perkebunanya. Selain cocok untuk ditanami komoditas kelapa sawit dan karet, desa Binamang juga cocok dikembangkan perkebunanya pada komoditas coklat, gambir dan gaharu. Hal ini juga didukung oleh banyaknya jumlah lahan marginal (tidur) yang belum dimanfaatkan di Desa Binamang. Akan tetapi, sebagian lahan marginal ini merupakan kawasan resapan danau PLTA Koto Panjang. Perlu di lakukan pemetaan dan klasifikasi secara jelas dan terperinci, terhadap lahan marginal (tidur) yang potensial dijadikan lahan perkebunan dan lahan marginal (tidur) yang merupakan kawasan resapan danau PLTA Koto Panjang. Hal ini dilakukan agar tidak terjadi permasalahan/konflik dikemudian hari. Selain itu, data pemetaan ini juga berguna untuk dijadikan data informasi bagi calon investor yang berniat menanamkan dananya pada bidang perkebunan di Desa Binamang

Untuk menginventarisir kawasan lahan marginal (tidur) yang bukan merupakan kawasan resapan danau PLTA Koto Panjang secara akurat, Tim dosen Jurusan Teknik Mesin Universitas Riau melaksanakan kegiatan pengabdian masyarakat di Desa Binamang, dalam bentuk pembuatan peta lahan marginal (tidur) yang potensial dijadikan lahan perkebunan/pertanian. Peta ini
\end{abstract}


dilengkapi dengan sistem informasi geospasial. Kegiatan pemetaan ini dilakukan dengan menggunakan metode pemotretan udara melalui Pesawat Terbang Tanpa Awak dengan melibatkan mahasiswa kukerta Univesitas Riau dan perangkat desa setempat. Kegiatan pemotretan udara ini dilakukan pada ketinggian 250 meter dari atas permukaan tanah. Dengan metode tersebut, seluruh area lahan marginal (tidur) yang ada di desa Binamang dapat dipetakan dengan cepat dan detail.

Berdasarkan perhitungan yang dilakukan melalui media peta foto udara yang telah diinjeksi dengan koordinat gps, didapat luas lahan marginal yang berpotensi untuk dikembangkan menjadi lahan perkebunan di Desa Binamang yaitu seluas 40 hektar. Hasil ini bisa menjadi acuan bagi stakeholder terkait dalam merencanakan pengembangan area perkebunan di Desa Binamang. Hasil peta foto udara juga bisa dimanfaatkan bagi pengambil kebijakan setempat dalam merencanakan tata ruang wilayah Desa Binamang.

Kata Kunci- Lahan, Desa, Marginal

\section{PENDAHULUAN}

Desa Binamang merupakan salah satu desa yang berada di Kecamatan XIII Koto Kampar. Desa ini memiliki luas wilayah sebesar $1.028 \mathrm{~km}^{2}$. Desa ini berada di area perbukitan dengan jenis tanah kuning berbatu kerikil. Desa binamang berbatasan langsung dengan kelurahan Batu Bersurat yang merupakan Ibu Kecamatan XIII Koto Kampar. Jarak dari kota Pekanbaru ke Desa Binamang, Kecamatan XIII Koto Kampar lebih kurang 110 km.

Desa binamang terbagi menjadi empat dusun, delapan Rukun Warga (RW) dan enam belas Rukun Tetangga (RT). Desa ini memiliki jumlah penduduk sebanyak 928 jiwa, yang terdiri dari 491 laki - laki dan dan 437 perempuan. Sebanyak 50 jiwa buta aksara, tamat SMP 300 orang, tamat SMA 200 orang, tamat akademi 50 orang, sarjana 50 orang. Kondisi ini menjadi salah satu faktor utama penyebab kemiskinan dan rawan pangan. Pendapatan perkapita masyarakat di Desa Binamang rata - rata dibawah Rp 1.500.000/bulan.

Sebagian besar penduduk desa binamang bekerja di bidang pertanian/ perkebunan. Komoditas perkebunan yang paling banyak ditanami yaitu karet dan kelapa sawit. Luas area yang ditanami karet dan kelapa sawit di desa Binamang masing - masing sebesar 429 hektar dan 138 hektar [1].

Wilayah Desa Binamang berpotensi untuk dikembangkan area perkebunanya. Selain cocok untuk ditanami komoditas kelapa sawit dan karet, desa Binamang juga cocok dikembangkan perkebunanya pada komoditas coklat, gambir dan gaharu. Hal ini juga didukung oleh jumlah lahan marginal (tidur) yang belum dimanfaatkan di Desa Binamang juga masih banyak. Akan tetapi, sebagian lahan marginal ini merupakan kawasan resapan danau PLTA Koto Panjang. Perlu di lakukan pemetaan dan klasifikasi secara jelas dan terperinci terhadap lahan marginal (tidur) yang potensial dijadikan lahan perkebunan/pertanian dan lahan marginal yang merupakan kawasan resapan danau PLTA Koto Panjang. Hal ini dilakukan agar tidak terjadi permasalahan/konflik dikemudian hari. Selain itu, data pemetaan ini juga berguna untuk dijadikan data informasi bagi calon investor yang berniat menanamkan dananya pada bidang perkebunan di Desa Binamang.

Berdasarkan pada permasalahan diatas, Tim dosen Jurusan Teknik Mesin Universitas Riau melaksanakan kegiatan pengabdian di Desa Binamang dalam bentuk pembuatan peta lahan marginal (tidur) yang potensial dijadikan lahan perkebunan/pertanian. Peta ini dilengkapi dengan sistem informasi geospasial. Kegiatan pemetaan ini dilakukan dengan menggunakan metode pemotretan udara melalui Pesawat Terbang Tanpa Awak dari ketinggian 250 meter diatas permukaan tanah. Dengan metode tersebut, seluruh area lahan marginal (tidur) yang ada di desa Binamang dapat dipotret dengan cepat. Data berupa foto udara kemudian diolah menggunakan software agisoft photoscan. Hasilnya di validasi dengan perangkat desa dan stakeholder terkait agar didapatkan peta lahan lahan marginal (kosong) dengan dilengkapi sistem informasi geospasial. Peta lahan marginal (kosong) ini, selain dapat digunakan oleh perangkat desa dan perangkat kecamatan, dalam menginventarisir lahan marginal (tidur) yang potensial dijadikan area perekebunan [2], juga dapat dijadikan sebagai data acuan untuk merencanakan pengembangan area perkebunan/pertanian di Desa Binamang. 


\section{METODE}

Pengabdian kepada masyarakat dalam bentuk pembuatan peta lahan marginal (kosong) yang potensial dijadikan lahan perkebunan di Desa Binamang, Kecamatan XIII Koto Kampar, Kabupaten Kampar, dapat dikelompokkan menjadi empat tahap yaitu:

\subsection{Tahap awal}

Kegiatan tahap awal yang dilakukan berupa survey awal ke lokasi beserta diskusi/shearing dengan calon desa mitra. Diskusi awal ini selain bertujuan untuk menggali permasalahan terkait kondisi umum masyarakat dan potensi pengembangan area perkebunan di Desa Binamang, juga ditujukan untuk mengkoordinasikan rencana pelaksanaan kegiatan, menggali potensi keterlibatan mitra serta pihak lainya. Kegiatan survey awal ini dilaksanakan dalam rangka menysusun proposal pengabdian untuk mendapatkan analisis situasi terhadap khalayak masyarakat (mitra).

\subsection{Persiapan Kegiatan Pengabdian Masyarakat dalam Bentuk Pembuatan Wahana Terbang Tanpa Awak}

Pembuatan wahana pesawat terbang tanpa awak yang akan digunakan sebagai wahana yang akan menjalankan misi pemetaan melalui foto udara, diawali dengan melakukan pencetakan bagian badan pesawat terbang tanpa awak. Proses pencetakan badan pesawt terban tanpa awak dilakukan dengan metode hand layup. Serat kaca berbentuk kain dengan densitas 130 gsm digunakan sebagai material utama pembentuk badan pesawat. Serat kaca ini dipadu dengan resin epoxy dengan perbandingan massa 1:1, agar dihasilkan badan pesawat terbang tanpa awak yang kuat namun tetap ringan. Berikut ditampilkan gambar 1 proses pencetakan badan pesawat terbang tanpa awak.

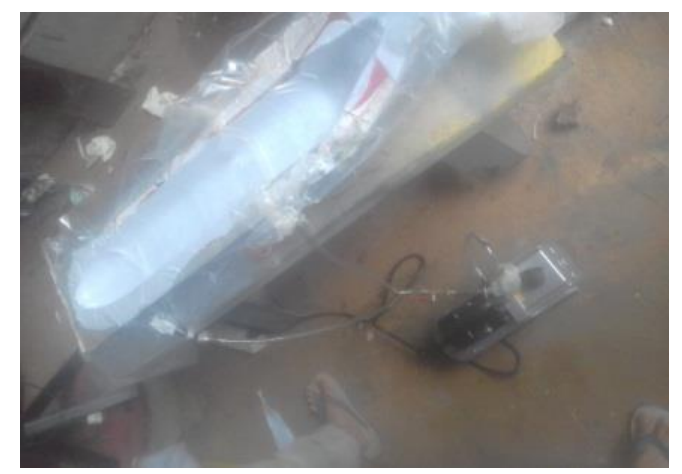

Gambar 1. Proses Pencetakan Badan Pesawat Terbang Tanpa Awak

Proses pencetakan bagian badan pesawat dilakukan sebanyak dua kali, yaitu pada bagian badan bawah dan bagian badan atas. Kedua hasil cetakan badan pesawat ini kemudian disatukan dengan menggunakan lem epoxy dan tali fiber. Proses penyatuan kedua badan pesawat terbang tanpa awak ini memakan waktu sebanyak 12. Hal ini dikarenakan waktu yang dibutuhkan lem epoxy agar bisa kering dengan sempurna yaitu selama 12 jam penuh. Berikut ditampilkan gambar 2 proses penyatuan kedua bagian badan pesawat terbang tanpa awak.

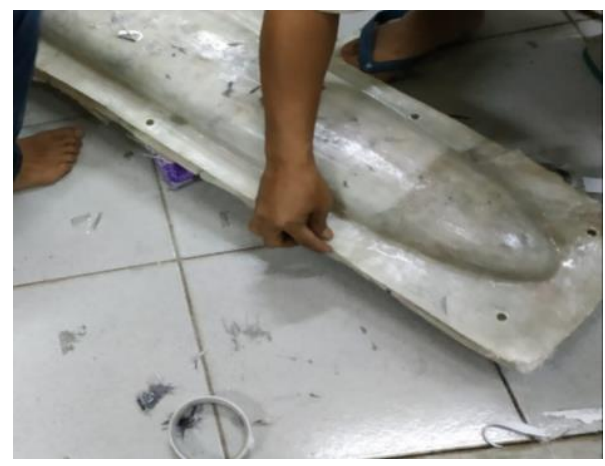

Gambar 2. Proses penyatuan kedua bagian badan pesawat terbang tanpa awak 
Setelah bagian badan pesawat terbang tanpa awak selesai dicetak, proses dilanjutkan dengan pendempulan dan pengecatan. Proses ini merupakan tahapan terakhir dari pembuatan bagian badan pesawat terbang tanpa awak. Proses pendempulan dan pengecatan ini memakan waktu sebanyak 7 hari dengan kondisi cuaca yang cerah. Berikut ditampilkan gambar 3 hasil akhir dari pembuatan badan pesawat terbang tanpa awak.

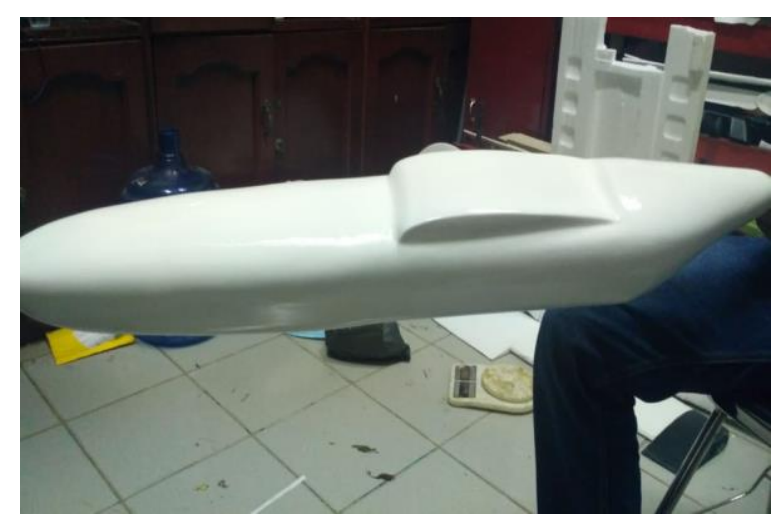

Gambar 3. Hasil akhir dari pembuatan badan pesawat terbang tanpa awak

Pembuatan bagian sayap dan ekor wahana pesawat terbang tanpa awak, dilakukan dengan menggunakan material foam core composite. Material ini dipilih karena pertimbangan massa yang ringan namun tetap kuat untuk menahan beban aerodinamik yang bekerja pada saat wahana terbang diudara. Proses pembuatan bagian sayap sama persis dengan proses pembuatn ekor wahana pesawat terbang tanpa awak. Proses ini diawali dengan membentuk material foam tipe keras menggunakan hot wire. Setelah sayap dan ekor berhasil dibentuk, selanjutnya dilakukan proses laminasi dengan menggunakan resin epoxy dan serat kaca. Terakhir, sayap dan ekor dilaminasi dengan cutting sticker agar didapat hasil pembuatan sayap dan ekor sesuai dengan warna yang direncanakan.

Setelah bagian badan, sayap dan ekor berhasil dibuat, proses penyatuan ketiga bagian airframe pesawat terbang tanpa awak ini dilakukan dengan menggunakan material sambungan baut, mur, lem bakar, aluminium spar dan aluminium hollow. Metode sambungan ini dipilih agar ketiga bagian utama dari pesawat terbang tanpa awak ini dapat dibongkar pasang, sehingga memudahkan tim pengabdian dalam melakukan mobilisasi wahana pesawat terbang tanpa awak.

Tahapan berikutnya dari pembuatan wahana pesawat terbang tanpa awak yaitu proses installasi perangkat elektronik. Proses ini diawali dengan memasang bagian motor pada bagian sayap wahana. Proses ini dilanjutkan dengan memsang motor penggerak aileron, elevator dan rudder pada wahana. Terakhir dilakukan installasi perangkat esc, batere dan flight controller pada wahana. Berikut ditampilkan gambar 4 hasil pembuatan pesawat terbang tanpa awak.

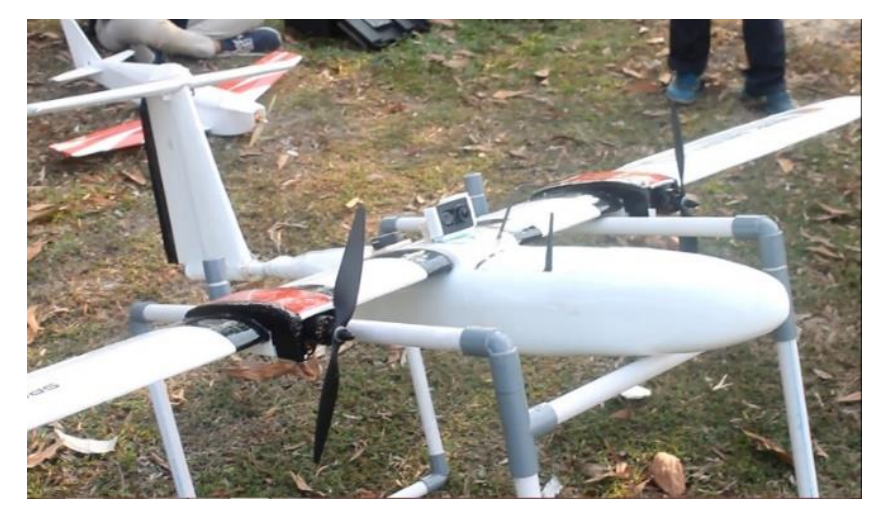

Gambar 4. Hasil pembuatan pesawat terbang tanpa awak.

Setelah wahana pesawat terbang tanpa awak berhasil diproduksi berdasarkan desain yang telah ada, selanjutnya dilakukan proses uji terbang wahana pesawat terbang tanpa awak dalam melakukan 
misi aerial mapping. Proses uji terbang ini dilakukan dengan dua mode terbang. Pada saat takeoff dan landing, wahana terbang menggunakan mode manual yang dikendalikan langsung oleh pilot melalui remot control. Pada saat terbang pada kondisi jelajah pada ketinggian 150 meter, wahana terbang pada mode autonomous yang koordinat terbangnya dipandu oleh perangkat GPS. Berikut ditampilkan gambar 5 Persiapan uji terbang wahana dalam melakukan misi aerial mapping.

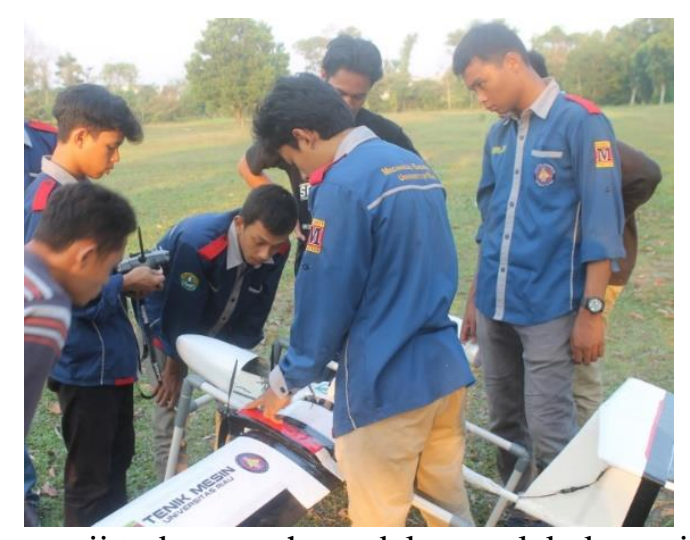

Gambar 5. Persiapan uji terbang wahana dalam melakukan misi aerial mapping

Tahapan terakhir dari persiapan pelaksanaan kegiatan pengabdian yaitu mempersiapkan peralatan yang diperlukan untuk foto udara meliputi dua buah wahana terbang tanpa awak (UAV). Selain itu juga dipersiapkan rencana kerangka jaring kontrol horizontal untuk pengukuran GPS. Kemudian hal-hal yang berkaitan dengan izin kegiatan pengambilan data, dikoordinasikan dengan perangkat desa setempat.

\subsection{Pelaksanaan}

Sebelum pemotretan udara dilakukan, perencanaan jalur terbang dibuat terlebih dahulu. Jalur terbang dibuat agar memudahkan pengambilan foto dan pengontrolan posisi UAV. Pemotretan foto udara yang baik dapat dilihat dari kualitas ketajaman foto dan penampakan foto udara [3]. Foto udara dibuat memiliki overlap $60 \%$ dan sidelap $30 \%$. Pemotretan foto udara dilakukan pada siang hari agar diperoleh hasil yang terang. Waktu yang diperlukan untuk menyelesaikan pemotretan seluruh lahan marginal (tidur) memakan waktu selama 3 jam.

Kegiatan pemotretan udara diawali dengan tahapan installasi perangkat airframe dan perangkat elektronik wahana. Proses ini menghabiskan waktu selama 1 jam lebih dilokasi pengabdian. Selanjutnya dilakukan proses upload jalur terbang yang direncanakan pada modul flight controller wahana. Setelah selesai, proses preflight check dilakukan untuk memastikan tidak ada kesalahan prosedur sedikitpun yang terjadi pada wahana pesawat terbang tanpa awak. Berikut ditampilkan gambar 6 tim di lokasi pengabdian sesaat setelah dilakukan proses preflight check.

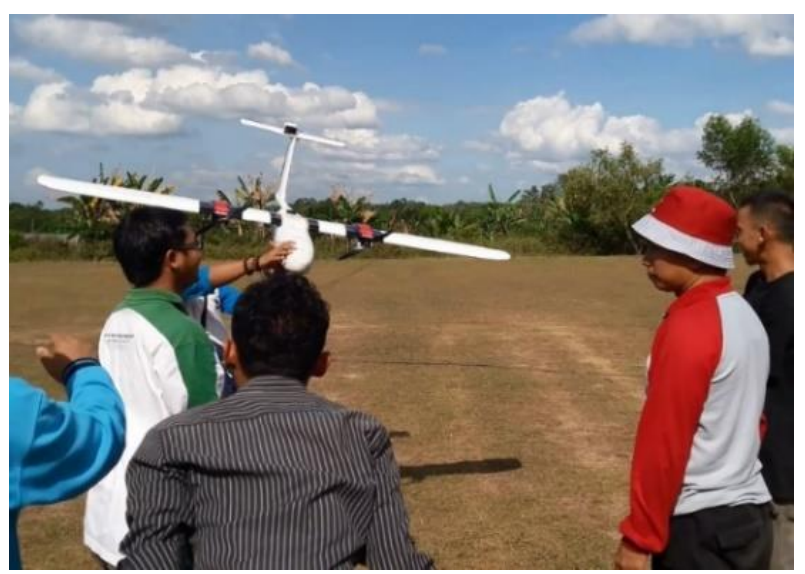

Gambar 6. Tim di lokasi pengabdian sesaat setelah dilakukan proses preflight check. 
Setelah selesai dilakukan proses preflight check, selanjutnya wahana dilepas landaskan dengan mode hand launch. Take off mode hand lauch dpilih karena dilokasi pengabdian tidak terdapat landasan memadai bagi wahana untuk takeoff menggunakan roda pendarat. Pada saat take off, wahana dikontrol secara manual sampai mencapai ketinggian 250 meter dari atas permukaan tanah. Ketinggian ini diketahui dari sensor yang terdapat pada wahana, dimana datanya dikirim langsung pada ground control. Setelah wahana mencapai ketinggian yang diinginkan, mode terbang wahana dialihkan pada mode autonomous. Pada mode inilah wahana melakukan proses pemotretan udara secara otomatis sesuai dengan posisi koordinat yang telah dilakukan sebelumnya. Berikut ditampilkan gambar 7 proses take off wahana pesawat terbang tanpa awak.

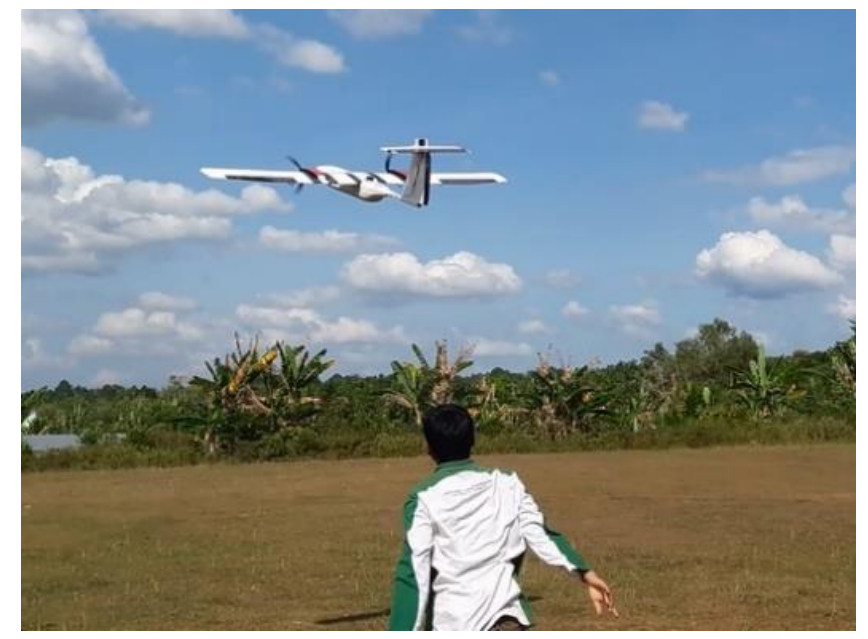

Gambar 7. Proses take off wahana pesawat tanpa awak di lokasi pengabdian.

Hasil dari kegiatan pemotretan udara dalam bentuk foto, kemudian diolah menggunakan software mosaic global mapper, agisoft dan arcmap. Output dari proses pada ketiga software ini yaitu dihasilkan sebuah peta foto udara dengan resolusi tinggi pada lahan marginal di Desa Binamang, Kecamatan XIII Koto Kampar. Peta foto udara ini kemudian di cetak pada banner dengan ukuran panjang 2 meter dan lebar 1,5 meter. Hasil cetakan dan data softcopynya kemudian diserahkan kepada Kepala Desa Binamang disertai dengan penjelasan penggunaan peta dalam format KML agar bisa di masukan pada software google earth. Penjelasan juga disertai dengan petunjuk cara melakukan proses editing keterangan (legenda) pada peta. Berikut ditampilkan gambar 8 hasil pemetaan udara pada lahan marginal di desa Binamang. Berikut ditampilkan gambar 3.7 hasil salah satu foto udara yang belum dilakukan proses orthomosaic.

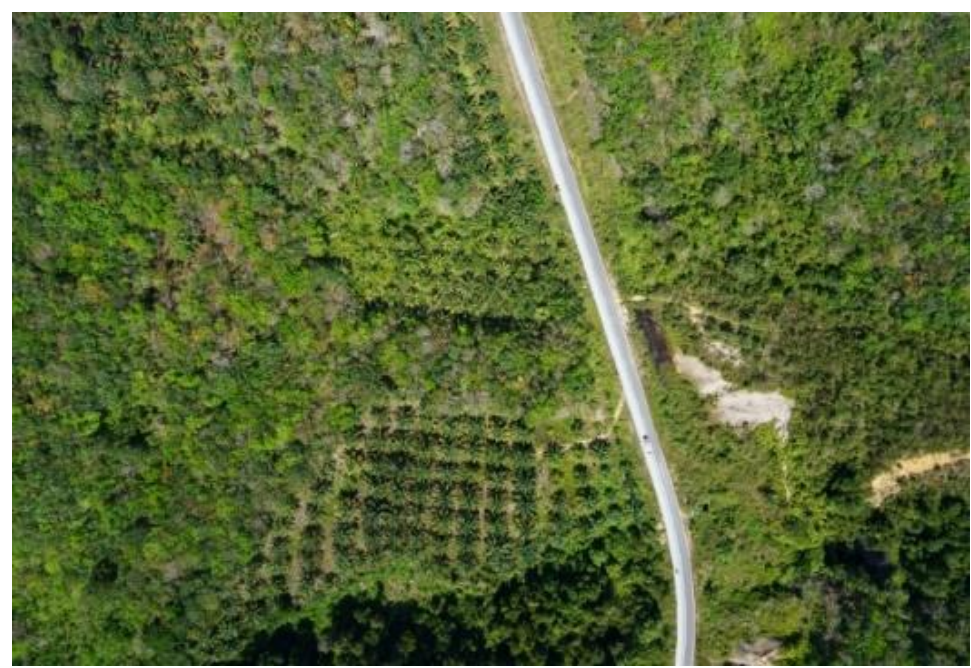

Gambar 8. Hasil salah satu foto udara yang belum dilakukan proses orthomosaic 


\section{HASIL DAN PEMBAHASAN}

Kegiatan pengabdian di Desa Binamang, Kecamatan XIII Koto Kampar, Kabupaten Kampar, menghasilkan foto udara pada lahan marginal yang berpotensi untuk dijadikan lahan pertanian atau lahan perkebunan. Berdasarkan perhitungan yang dilakukan melalui media peta foto udara yang telah diinjeksi dengan koordinat gps, didapat luas lahan marginal yang berpotensi untuk dikembangkan menjadi lahan perkebunan di Desa Binamang yaitu seluas 40 hektar. Hasil ini bisa menjadi acuan bagi stakeholder terkait dalam merencanakan pengembangan area perkebunan di Desa Binamang. Hasil peta foto udara juga bisa dimanfaatkan bagi pengambil kebijakan setempat dalam merencanakan tata ruang wilayah Desa Binamang. Berikut ditampilkan gambar 9 hasil pemetaan udara pada lahan marginal di desa Binamang.

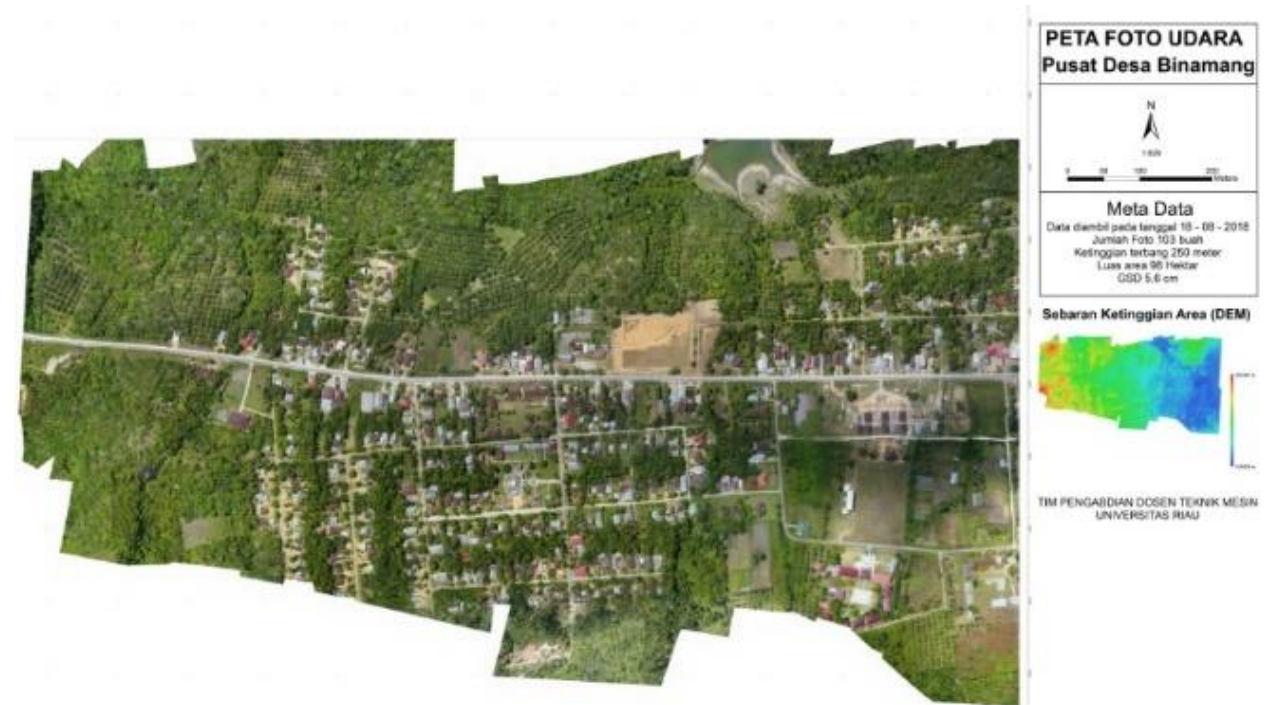

Gambar 9. Hasil pemetaan udara pada lahan marginal di desa Binamang

\section{KESIMPULAN}

Kegiatan pengabdian di Desa Binamang dalam bentuk pembuatan petta foto udara pada lahan marginal, menghasilkan foto udara dengan resolusi tinggi sebanyak 134 buah. Foto udara ini berhasil diolah menggunakan software agisoft photoscan dengan output berupa kesatuan foto udara dalam bentuk peta citra resolusi tinggi pada lahan marginal di Desa Binamang. Berdasarkan perhitungan yang dilakukan melalui media peta foto udara yang telah diinjeksi dengan koordinat gps, didapat luas lahan marginal yang berpotensi untuk dikembangkan menjadi lahan perkebunan di Desa Binamang yaitu seluas 40 hektar.

Peta foto udara dengan citra resolusi tinggi pada lahan marginal yang terdapat di Desa Binamang dapat digunakan sebagai dasar atau pertimbangan dalam merencanakan program lahan produktif. Data terkait luas dan posisi lahan marginal dapat diidentifikasi dengan jelas dikarenakan peta ini dilengkapi dengan koordinat gps.

\section{SARAN}

Peta foto udara dengan citra resolusi tinggi pada lahan marginal yang terdapat di Desa Binamang dapat digunakan sebagai dasar atau pertimbangan dalam merencanakan program lahan produktif. Data terkait luas dan posisi lahan marginal dapat diidentifikasi dengan jelas dikarenakan peta ini dilengkapi dengan koordinat gps. 


\section{UCAPAN TERIMA KASIH}

Penulis menyadari bahwa dalam kegiatan pengabdian ini telah banyak pihak yang membantu. Oleh karena itu kami mengucapkan terima kasih kepada :

1. Bapak Prof. Dr. Almasdi Syahza, SE., MP selaku Ketua Lembaga Penelitian dan Pengabdian Kepada Masyarakat Universitas Riau

2. Dekan Fakultas Teknik Universitas Riau

3. Ketua Jurusan Teknik Mesin Universitas Riau

4. Rekan - rekan dosen Jurusan Teknik Mesin Universitas Riau

5. Aparat desa dan tokoh masyarakat di Desa Binamang, Kecamatan XIII Koto Kampar, Kabupaten Kampar, Riau.

\section{DAFTAR PUSTAKA}

[1] Badan Pusat Statistik Kabupaten Kampar. Kecamatan XIII Koto Kampar Dalam Angka. 2017. Kampar.

[2] Fauzy, Achmad. Evaluasi Dan Pemetaan Potensi Desa Mitra Dppm UII. Jurnal Inovasi dan Kewirausahaan. $2015 ; 4(1): 55$-57.

[3] Hidayat,(2005), Seri Panduan Pemetaan Partisipatif No. 2 - Mengenalkan Pemetaan Partisipatif,Garis Pergerakan, Bandung. 